\title{
Where have all the investors gone?: The case for consolidation
}

\author{
To get Wall Street interested again, bioentrepreneurs need to build collaborations \\ that can produce predictable product sales, gross margins, and earnings growth.
}

\author{
Robert S. Esposito and Marc J. Ostro
}

They may lack passion and romance, but they're still getting hitched in record numbers. Indeed, pharmaceutical companies are announcing mergers and alliances in business journals frequently enough to rival springtime wedding announcements in the society pages. Yet in the midst of all this matchmaking, biotechnology firms are often left waiting in the wings, hoping to catch a bouquet thrown by an institutional investor rather than seeking out a complementary partner. These weddings suggest that the business model governing biotechnology investment has changed-perhaps permanently.

\section{Grow up!}

Gone are the days when institutional investors threw money at early-stage biotechnology companies with abandon. Today, with the proliferation of biotechnology firms, few investors have the inclination, the information, the technical capabilities, or the time to separate the rising stars from the "also-rans." Also, many investors now view early-stage financing as too risky. The alternative, investing in numerous "inexpensive" later-stage companies-some that even have products near or on the market, or lower-risk platform technology companies, offers far fewer risks.

But even these later-stage companies are having a tough time selling themselves. Investors have learned through experience that it is difficult to gauge a biotechnology product's sales potential. Companies with annual sales as high as \$50-100 million have had dismal valuations because their margins are simply not high enough. Institutional investors want to see a clear path to quality earnings through the tried-and-true Wall Street model of sustained and predictable product sales, gross margins, and earnings growth.

Robert S. Esposito is national partner-incharge and Marc J. Ostro is senior managing director at KPMG Peat Marwick LLP, Health Care Transaction Services, P.O. Box 7468, Princeton NJ 08543 (resposit@kpmg.com). The views and opinions are those of the authors and do not necessarily reflect the views and opinions of KPMG.
This inability to show sustained margins on sales is changing investors' attitudes toward biotechnology's propensity for long development times, large cash consumption, and substantial technological, medical, and regulatory risk. In the early 1990s, many investors indulged these risks because they believed that if a company could simply get its products to market, they would realize substantial, venture-type investment returns. Unfortunately, this assertion proved false for many investors.

As a result, the prevailing financial mantra on Wall Street is, "Why take the risk?" This has resulted in diminished access to capital for a majority of the 330 public and 1,500 private US biotechnology companies. Investors now increasingly view biotechnology as "public venture capital" at a high price. These investors are exhibiting a genuine "Show me the money" investment mentality.

The bottom line is that biotechnology can no longer use its youth, or the hype of its future potential, as an excuse. The vast majority of institutional investors believe it should have grown up and produced more predictable, sustainable operating results by now.

\section{Wooing them back}

Biotechnology must offer investors some substantive changes, the most viable strategy being industry-wide consolidation. There are number of factors driving this necessity. First, too many companies are chasing too few and, in fact, a shrinking number of investment dollars. Second, not enough qualified senior management exists to staff the 1,800-odd companies. Third, too many companies are competing for the same niche disease markets, such as CMV retinitis and Kaposi's sarcoma. Fourth, the likelihood of an extraordinary number of patent lawsuits is becoming greater as more products are launched using similar technologies. Fifth, too many companies do not possess diversified portfolios to help offset the technology, regulatory, and market acceptance risks of a product launch.

Strategic combinations can address all of these issues. Unfortunately, most merger and acquisition activity to date has occurred not because of potential synergies that may be realized, but rather as a way to save one or both of the companies involved. A merger should be considered only if the transaction solves several critical operating, financial, regulatory, and/or commercialization problems, and aligns the combined company more favorably with the traditional Wall Street model. Alternatively, creating a broad-based technology platform capable of attracting partnerships with other product companies that can move the company closer to earnings growth is also a favorable strategy.

Since the logic is compelling, why don't more of these transactions occur? In some cases, the boards of directors of emerging life science companies, often comprised of venture capitalists, are exquisitely sensitive to dilution, as it affects the ability of these investors to cash out at attractive prices. In other cases, senior management wants to protect existing jobs. For still others, an emotional attachment between entrepreneurs and the companies they have created overshadows logic. Finally, some boards and their management teams do not appreciate the urgency of creating shareholder value on a sustained basis in the near or immediate term.

\section{Conclusions}

Management may have difficulty adopting the cold, analytical approach exhibited by big pharmaceutical company executives when assessing the wisdom of a merger or a business collaboration. But to compete successfully in today's investment arena, biotechnology companies need to look at the future and realistically evaluate their business plans.

Answering such questions as, "Will the company be able to achieve sustained profitability and quality earnings in the next few years?" or "Are the products differentiated enough to remain successful over the long term?" or "Do we have enough cash on hand to get the job done if access to capital under reasonable terms is denied?" will give you a sense of where your company stands. If the answers are negative, then a strategic M\&A or other form of business collaboration should be considered. If you did not catch the bouquet at the last wedding, perhaps it means you need a whole new set of friends. 